\title{
Article \\ Comparative Study of Antimicrobial Properties of Bee Venom Extracts and Melittins of Honey Bees
}

\author{
Jakkrawut Maitip ${ }^{1}$ (), Wannapha Mookhploy ${ }^{2}$, Supharerk Khorndork ${ }^{2}$ and Panuwan Chantawannakul ${ }^{2,3, *(1)}$ \\ 1 Faculty of Science, Energy and Environment, King Mongkut's University of Technology North Bangkok, \\ Rayong Campus, Rayong 21120, Thailand; jakkrawut.m@sciee.kmutnb.ac.th \\ 2 Bee Protection Laboratory, Department of Biology, Faculty of Science, Chiang Mai University, \\ Chiang Mai 50200, Thailand; wannapha.mookhploy@gmail.com (W.M.); k.supharerk1@gmail.com (S.K.) \\ 3 Environmental Science Research Center (ESRC), Faculty of Science, Chiang Mai University, \\ Chiang Mai 50200, Thailand \\ * Correspondence: panuwan@gmail.com
}

Citation: Maitip, J.; Mookhploy, W.; Khorndork, S.; Chantawannakul, P. Comparative Study of Antimicrobial Properties of Bee Venom Extracts and Melittins of Honey Bees. Antibiotics 2021, 10, 1503. https://doi.org/ 10.3390/antibiotics 10121503

\section{Academic Editors:}

Rungroch Sungthong and

Rosa Alduina

Received: 9 November 2021

Accepted: 4 December 2021

Published: 8 December 2021

Publisher's Note: MDPI stays neutral with regard to jurisdictional claims in published maps and institutional affiliations.

Copyright: (c) 2021 by the authors. Licensee MDPI, Basel, Switzerland. This article is an open access article distributed under the terms and conditions of the Creative Commons Attribution (CC BY) license (https:/ / creativecommons.org/licenses/by/ $4.0 /)$.

\begin{abstract}
Bee venom (BV), or apitoxin, is a complex substance produced by a gland in the abdominal cavity of bees. The main component of BV is melittin, which is a largely studied substance due to its biological properties. To date, the most well-known bee venom and melittin are derived from domesticated honey bees, while venom and melittin derived from wild honey bees have been under-investigated. Hence, this study primarily reports the antimicrobial activities of bee venom and synthetic melittin derived from four different honey bee species (Apis mellifera, A. cerana, A. dorsata, and A. florea) in Thailand. All the bee venom extracts and melittins showed more robust antibacterial activities against Gram-positive (Bacillus subtilis, Micrococcus luteus, Staphylococcus aureus, S. aureus MRSA, and S. epidermidis) than Gram-negative bacteria (Escherichia coli, Klebsiella pneuminiae, and Salmonella typhimurium) or a fungus (Candida albicans), while the synthetic melittins also have antimicrobial activity at higher concentrations than the bee venom extract. Furthermore, the $A$. cerana venom extract showed the highest activity against the tested bacteria, followed by A. mellifera, A. florea, and $A$. dorsata. Therefore, $A$. cerana venom may be further developed for use in medical applications as a potential alternative agent against Gram-positive bacteria and antibiotic-resistant bacteria.
\end{abstract}

Keywords: bee venom; eastern honey bee; apitherapy

\section{Introduction}

The honey bee is an essential economic insect; it is widely used in agriculture as a pollinator and produces several natural products. These products, such as honey, pollen, royal jelly, propolis, and, especially, honey bee venom, or Apitoxin, can be applied in the fields of pharmacy and medicine. Bee venom is produced by the venom glands located in the posterior of the abdomen and is stored in the venom reservoir. The venom is released through the sting apparatus to protect the bee from harm [1]. The Western honey bee's (Apis mellifera) venom has been used since the ancient Egyptian era (4000 BC) [2]. Traditional medicine has been utilized to treat several diseases, including arthritis, rheumatism, pain, cancerous tumors, and skin diseases [3]. Extensive research has been carried out regarding the Western honey bee; it was found that its venom has multiple effects, consisting of anti-inflammatory [4], antimicrobial [2,5-7], and antioxidant activities [4,8].

Honey bee venom contains a variety of active substances, including peptides (e.g., melittin, apamin, adolapin, and mast cell degranulating peptide); enzymes (e.g., phospholipase A2 (PLA 2 ) and hyaluronidase); biologically active amines (e.g., histamine and epinephrine); and non-peptide components (including lipids, carbohydrates, and free amino acids) [2]. The major component of bee venom is melittin, which accounts for $40-50 \%$ of the venom's dry weight [3]. Melittin is a cationic peptide and an amphipathic peptide of 26 amino acid residues; residues 1-20 are hydrophobic in the amino-terminal 
end [9], and residues 21-26 are hydrophilic in the carboxy-terminal end. It can dissolve in water as a monomer or tetramer [10] and is a principal active component of bee venom that displays high antimicrobial and cytotoxic properties [11].

To our knowledge, the antimicrobial activities of different bee venoms and melittins have not yet been investigated. The venom of Apis mellifera has been widely studied in Hymenoptera, whereas there is limited information regarding the native honey bee's venom. Few studies have reported on the antioxidant activity of the crude venom of A. dorsata [8] and anticancer activity of the melittin of $A$. florea.

Interestingly, differences between different honey bee species affect the compositions of each of their venoms. The melittin contents vary in different honey bees; for example, the levels in A. dorsata, A. mellifera, A. florea, and A. cerana were $95.8 \pm 3.2 \%, 76.5 \pm 1.9 \%$, $66.3 \pm 8.6 \%$, and $56.8 \pm 1.8 \%$, respectively [8]. The size of the venom gland and venom sac secretion depends on the body size of the honey bee, which means $A$. dorsata possesses the largest venom gland and venom sac, followed by A. cerana, A. mellifera, and A. florea. Moreover, the amount and composition of the lipid, protein, carbohydrate, and alkaline phosphatase are usually the highest in A. cerana, followed by A. mellifera and A. florea. The antimicrobial activity of bee venom and melittin from different honey bee species is poorly understood. This study collected crude venom from four honey bee species, and the melittin genes were discovered and used as the template for melittin synthesis. The antimicrobial activity of crude venom and synthetic melittin were compared against bacteria and a fungus.

Our findings showed that the crude venom and melittin taken from A. cerana are the most effective in antimicrobial activity against Gram-positive bacteria and MRSA as opposed to Gram-negative bacteria and the fungus, followed by A. mellifera, A. florea, and $A$. dorsata. The crude bee venom showed higher antimicrobial activity compared to synthetic melittin. Based on these results, we suggest that different honey bee species have different melittin amino acid compositions that affect the antimicrobial activity of their venom, and crude bee venom is more effective with regard to antimicrobial activity than melittin alone.

\section{Results}

\subsection{Melittin Sequence}

The total genomic DNA was extracted from native honey bees (A. florea and A. dorsata). The melittin gene sequences were obtained after PCR amplification of their genomic DNA deposited in GenBank (Table 1). To synthesize four types of melittin peptides, we used two melittin gene sequences derived in this study and the other two melittin gene sequences retrieved from the NCBI database (A. mellifera and A. cerana) as a template for melittin peptides synthesis (Table 1).

Table 1. Melittin peptide sequences of four honey bee species.

\begin{tabular}{ccccc}
\hline No. & Species & Accession No. & Amino Acid Sequences & Reference \\
\cline { 1 - 4 } 1 & A. mellifera & AFI40556 & GIGAVLKVLTTGLPALISWIKRKRQQG & [12] \\
\cline { 1 - 4 } 2 & A. cerana & P0DPR9.1 & GIGAVLKVLTTGLPALINWIKRKRQQG & \\
\hline 3 & A. florea & AMP82000 & GIGAILKVLATGLPTLISWIKNKRKQG & \multirow{2}{*}{ This study } \\
\cline { 1 - 4 } 4 & A. dorsata & AMP81999 & GIGAILKVLSTGLPALISWIKRKRQEG & \\
\hline
\end{tabular}

The multiple sequence alignments of four melittin amino acid sequences were predicted using MUSCLE (Figure 1). The results showed that the melittin of A. mellifera (AMM) was similar to A. cerana (ACM) $(96.30 \%)$ but different from A. dorsata (ADM) $(85.19 \%)$ and A. florea (AFM) $(77.78 \%)$. 
Figure 1. Multiple sequence alignment of melittin peptides from four honey bee species via MUSCLE. An asterisk (*) indicates highly conserved sites, and a colon (:) and dot (.) represent less-conserved sites.

\subsection{Amino Acid Composition}

The amino acid composition of the melittin sequences was computed using ExPAsy ProtParam. The primary sequence analysis results are shown in Table 2. The results from the ExPAsy server (Table 2) indicated that the melittin from the different honey bees had 27 amino acids, and the protein had an average molecular weight that ranged from 2876.52 to $2931.56 \mathrm{Da}$. The similarity of the amino acid composition ranged from $77.78 \%$ to $96.3 \%$. The analysis revealed that the most abundant amino acid residues in melittin are glycine, leucine, isoleucine, and lysine. Based on the instability index (II), ExPAsy ProtParam classified the AMM and ADM as unstable (II > 40) and classified the ACM and AFM as stable (II $<40)$. The computed $\mathrm{pI}$ values of all the melittin samples were higher than 7 , which indicated that these melittins were basic in nature. The extinction coefficient ( 5500) indicated that the quantity of light that the protein could absorb was computed using tyrosine, tryptophan, and cysteine, while the aliphatic index ranged from 130 to 133.7, GRAVY ranged from 0.148 to 0.281 , and the instability index ranged from 34.64 to 50.58 .

Table 2. Amino acid composition (\%) and physicochemical parameters of melittin from four honey bee species computed by ExPAsy ProtParam and HeliQuest. Shading indicates the four most abundant amino acids in each melittin.

\begin{tabular}{ccccc}
\hline & AMM & ACM & AFM & ADM \\
\hline No. of AA & 27 & 27 & 27 & 27 \\
Mw (Da) & 2904.54 & 2931.56 & 2876.52 & 2905.52 \\
pI & 12.02 & 12.02 & 11.33 & 11.10 \\
GRAVY & 0.248 & 0.148 & 0.281 & 0.256 \\
Instability index (II) & 43.44 & 39.60 & 34.64 & 50.58 \\
Aliphatic index & 130 & 130 & 133.7 & 133.7 \\
Extinction coefficients & 5500 & 5500 & 5500 & 5500 \\
R- & 0 & 0 & 0 & 1 \\
R+ & 5 & 5 & 5 & 5 \\
Hydrophobicity $<\mathrm{H}>$ & 0.492 & 0.471 & 0.500 & 0.487 \\
Hydrophobic moment $<\mu \mathrm{H}>$ & 0.380 & 0.400 & 0.412 & 0.401 \\
Net Charge $(\mathrm{z})$ & 5 & 5 & 5 & 4 \\
Ala & 7.4 & 7.4 & 7.4 & 7.4 \\
Arg & 7.4 & 7.4 & 3.7 & 7.4 \\
Asn & 0 & 3.7 & 3.7 & 0 \\
Asp & 0 & 0 & 0 & 0 \\
Cys & 0 & 0 & 0 & 0 \\
Gln & 7.4 & 7.4 & 3.7 & 3.7 \\
Glu & 0 & 0 & 0 & 3.7 \\
Gly & 14.8 & 14.8 & 14.8 & 14.8 \\
His & 0 & 0 & 0 & 0 \\
Ile & 11.1 & 11.1 & 14.8 & 14.8 \\
Leu & 14.8 & 14.8 & 14.8 & 14.8 \\
Lys & 11.1 & 11.1 & 14.8 & 11.1 \\
Met & 0 & 0 & 0 & 0 \\
\hline & & & &
\end{tabular}


Table 2. Cont.

\begin{tabular}{ccccc}
\hline & AMM & ACM & AFM & ADM \\
\hline Phe & 0 & 0 & 0 & 0 \\
Pro & 3.7 & 3.7 & 3.7 & 3.7 \\
Ser & 3.7 & 0 & 3.7 & 7.3 \\
Thr & 7.4 & 7.4 & 7.4 & 3.7 \\
Trp & 3.7 & 3.7 & 3.7 & 3.7 \\
Tyr & 0 & 0 & 0 & 0 \\
Val & 7.4 & 7.4 & 3.7 & 3.7 \\
Pyl & 0 & 0 & 0 & 0 \\
Sec & 0 & 0 & 0 & 0 \\
\hline
\end{tabular}

AA: Amino acid, $\mathrm{M}_{\mathrm{W}}$ : the molecular weights, pI: isoelectric point, GRAVY: grand average of hydropathy, $\mathrm{R}-:$ the number of negative residues, and $\mathrm{R}+$ : the number of positive residues.

\subsection{Secondary Structure}

SOPMA computed the secondary structure of the melittin samples. The secondary structure of the melittin from four Apis species was predicted to contain an a-helix, b-turn, random coil, and extended strand, which revealed that the main structure of melittin is an a-helix (Figure 2). The a-helix structure in the four melittins analyzed ranged from $40.74 \%$ to $59.26 \%$, while the extended strand was least commonly found in melittin, ranging from $7.41 \%$ to $11.11 \%$, and not found in ACM (Table 3). The most common amino acid residues in melittin's a-helix regions were found to be glycine, leucine, isoleucine, and lysine. The significant difference between the amino acid composition in the different melittin samples was in the 18th position in the sequence. Melittin from A. mellifera, A. dorsata, and A. florea was found to contain asparagine (Asn), and melittin from A. cerana was found to contain serine (Ser). The change in the amino acid composition in the 18th position from asparagine to serine also changed the secondary structure, particularly in the a-helix region (Figure 2).

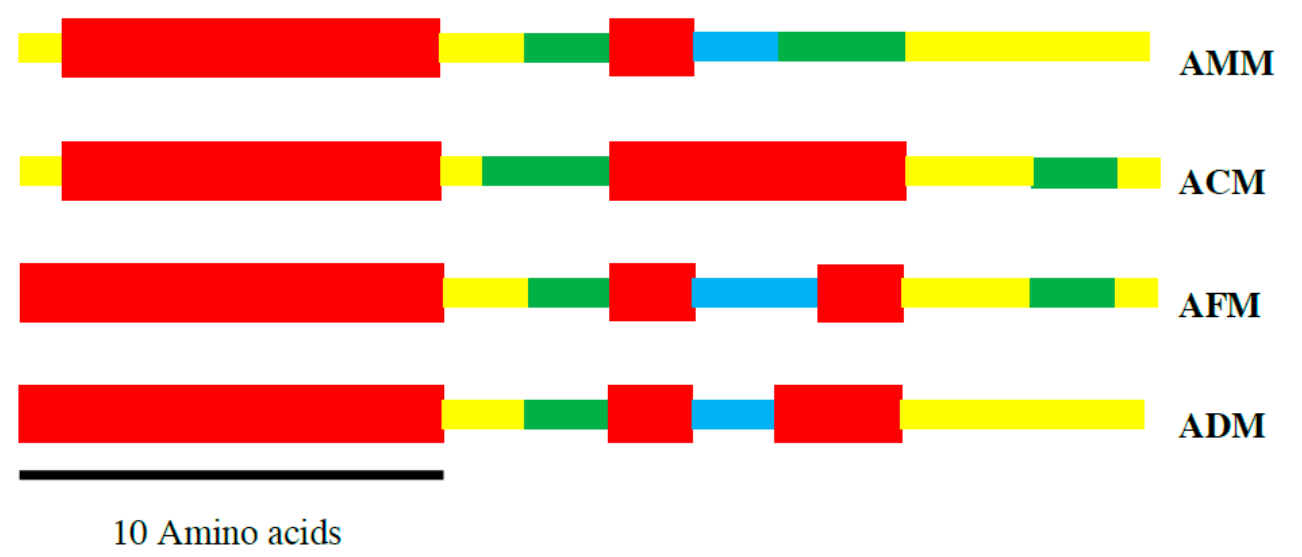

\section{$\boldsymbol{\alpha}$-helix $\quad \boldsymbol{\beta}$-turn $\square$ Ramdon coil $\square$ Extended strand}

Figure 2. Schematic representation of the predicted molecular architecture of melittin from four honey bee species based on the secondary structural analysis via SOPMA. The computation of melittin from different honey bees showed a predominance of $\alpha$-helices (red), followed by $\beta$-turns (yellow), random coils (green), and extended strands (blue). The scale bar represents the lengths of 10 amino acids.

\subsection{Primary Sequence Analysis}

The helical wheel plots of melittins from four Apis species predicted by HeliQuest [13] are shown in Figure 3. The length of the arrow indicates the extent of hydrophobicity. The color of the amino acid represents the basic residue (blue) and nonpolar residue (yellow), while the size of the circle represents the amino acid side chain. The hydropho- 
bicity $<\mathrm{H}>$ and hydrophobic moment $<\mu \mathrm{H}>$ values ranged from 0.471 to 0.500 and 0.380 to 0.412 , respectively.

Table 3. Representation of the melittin secondary structure from honey bees predicted via SOPMA (in percentages).

\begin{tabular}{ccccc}
\hline & $\alpha$-Helix & $\beta$-Turn & Random Coil & Extended Strand \\
\hline AMM & 40.74 & 33.33 & 18.52 & 7.41 \\
ACM & 59.26 & 22.22 & 18.52 & 0 \\
AFM & 51.85 & 22.22 & 14.82 & 11.11 \\
ADM & 55.55 & 29.63 & 7.41 & 7.41 \\
\hline
\end{tabular}

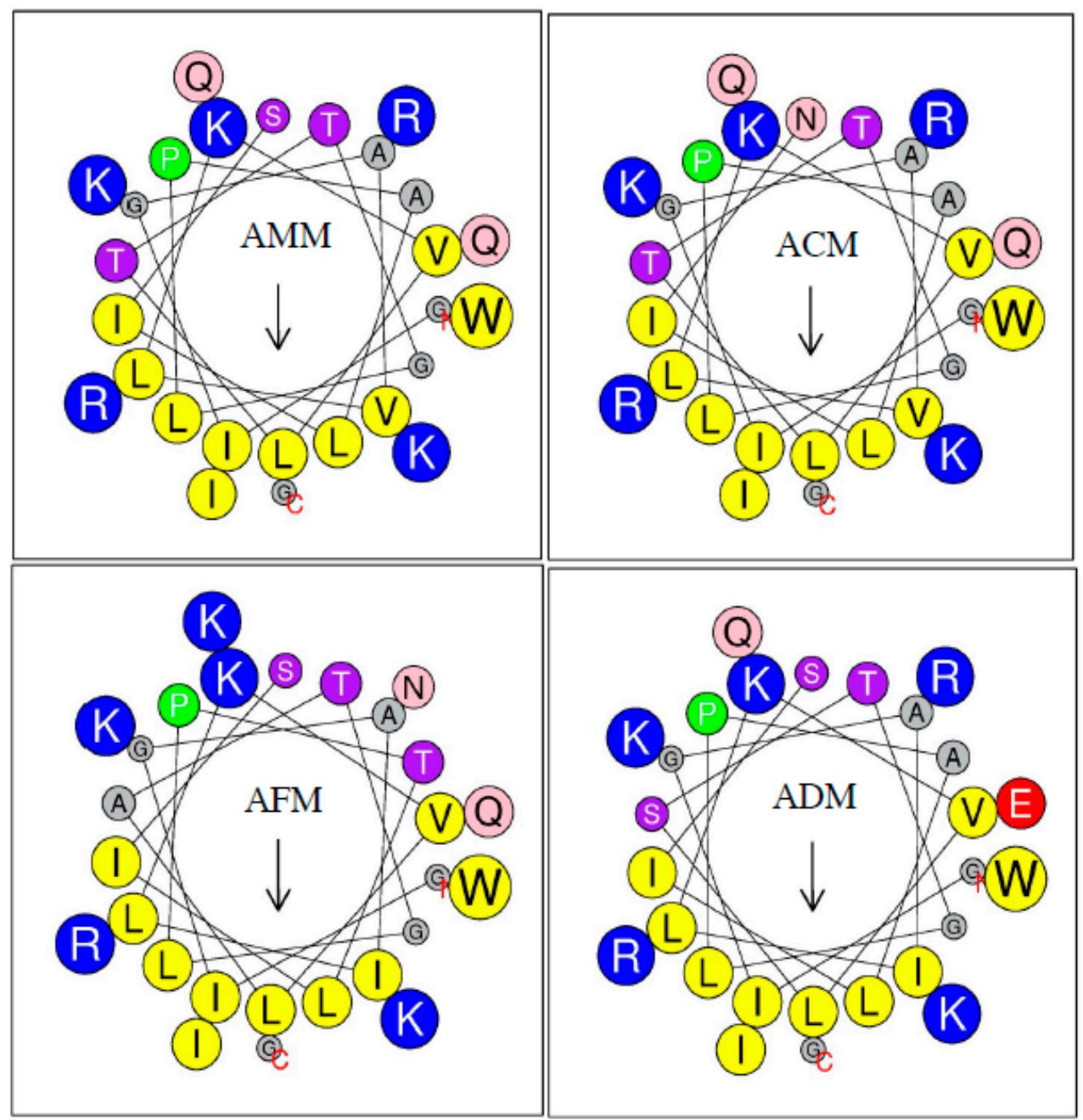

Figure 3. Helical wheel plots of the melittin from four honey bee species. The length of the arrow $(\downarrow)$ indicates the level of hydrophobicity $<\mathrm{H}>$ of the peptide. The size of the letter represents the size of the amino acid side chain. The hydrophilic and hydrophobic portions are labeled in blue and yellow circles, respectively.

\subsection{Physicochemical Parameters}

In this experiment, four melittin peptides were studied, including their physicochemical parameters and structures. The results shown in Table 2 reveal that melittin's isoelectric point (pI) ranged from 11.10 to 12.02 . ACM showed a high molecular weight of $2931.56 \mathrm{Da}$, while that of AFM presented a low molecular weight of $2876.52 \mathrm{Da}$. The molecular weights of ADM and AMM were approximately equal. The hydrophobicity of AMM was similar to that of AFM, but ACM possessed the lowest hydrophobicity. Only the melittin ADM pre- 
sented four positive net charges, while the remaining three melittins showed five positive net charges. The four melittins' grand average hydropathy (GRAVY) values were slightly positive, ranging from 0.148 to 0.281 . The melittins' aliphatic index (AI) was 130 for AMM and ACM and 133.7 for AFM and ADM. The melittins' instability index (II) was divided into two groups: II < 40 for ACM and AFM and II > 40 for AMM and ADM.

\subsection{Antimicrobial Activities of Four Crude Honey Bee Venoms}

The antimicrobial activity of crude venom from four honey bee species (A. mellifera, A. cerana, $A$. dorsata, and $A$. florea) against nine microorganisms were investigated using a two-fold serial dilution assay. The results showed that the MIC and MBC values of all the crude venoms against the Gram-positive bacteria were lower than those against the Gram-negative bacteria and yeast (Table 4). S. epidermidis showed MIC and MBC values at the lowest concentrations out of all the crude venom types. The crude venoms of A. cerana and $A$. mellifera did not display statistically significant differences with regard to the MIC and MBC values ( $p=0.395$ and 0.066 , respectively). Moreover, the crude venoms of $A$. cerana and $A$. mellifera possessed higher MIC and MBC values than the crude venoms of $A$. florea and $A$. dorsata (MIC and MBC, $p<0.05$ ). The crude venom of $A$. dorsata displayed low activity compared with the crude venom of $A$. florea (MIC, $p=0.013$ and $\mathrm{MBC}, p=0.028)$.

Table 4. Minimum inhibitory concentrations (MICs) and minimum bactericidal concentrations (MBCs) of crude honey bee venom from four honey bee species against pathogenic bacteria.

\begin{tabular}{|c|c|c|c|c|c|c|c|c|}
\hline \multirow{2}{*}{ Microorganism } & \multicolumn{4}{|c|}{ MIC ( $\mu \mathrm{g} / \mathrm{mL})$} & \multicolumn{4}{|c|}{ MBC/MFC ( $\mu \mathrm{g} / \mathrm{mL})$} \\
\hline & A. dorsata ${ }^{\mathrm{c}}$ & A. mellifera ${ }^{\mathrm{a}}$ & A. cerana ${ }^{\mathrm{a}}$ & A. florea $^{\mathbf{b}}$ & A. dorsata ${ }^{\mathrm{c}}$ & A. mellifera ${ }^{\mathrm{a}}$ & A. cerana ${ }^{\mathrm{a}}$ & A. florea $^{\mathrm{b}}$ \\
\hline \multicolumn{9}{|c|}{ Gram-negative bacteria } \\
\hline E. coli & $>400$ & $266.7 \pm 115.5$ & $200.0 \pm 0.0$ & $>400$ & $>400$ & $400.0 \pm 0.0$ & $400.0 \pm 0.0$ & $>400$ \\
\hline K. pneumonia & $>400$ & $400.0 \pm 0.0$ & $400.0 \pm 0.0$ & $>400$ & $>400$ & $400.0 \pm 0.0$ & $400.0 \pm 0.0$ & $>400$ \\
\hline S. typhimurium & $>400$ & $>400$ & $>400$ & $>400$ & $>400$ & $>400$ & $>400$ & $>400$ \\
\hline \multicolumn{9}{|c|}{ Gram-positive bacteria } \\
\hline B. subtilis & $133.3 \pm 57.7$ & $41.7 \pm 14.4$ & $37.5 \pm 21.7$ & $83.3 \pm 28.9$ & $133.3 \pm 57.7$ & $41.7 \pm 14.4$ & $37.5 \pm 21.7$ & $83.3 \pm 28.9$ \\
\hline M. luteus & $66.7 .0 \pm 28.9$ & $20.8 \pm 7.2$ & $16.7 \pm 7.2$ & $41.7 \pm 14.4$ & $66.7 \pm 28.9$ & $25.0 \pm 0.0$ & $25.0 \pm 0.0$ & $50.0 \pm 14.4$ \\
\hline S. aureus & $266.7 \pm 115.5$ & $41.7 \pm 14.4$ & $41.7 \pm 14.4$ & $83.3 \pm 28.9$ & $266.7 \pm 115.5$ & $41.7 \pm 14.4$ & $41.7 \pm 14.4$ & $83.3 \pm 28.9$ \\
\hline$M R S A$ & $>400$ & $66.7 \pm 28.9$ & $50.0 \pm 0.0$ & $200.0 \pm 0.0$ & $>400$ & $100.0 \pm 0.0$ & $66.7 \pm 28.9$ & $400.0 \pm 0.0$ \\
\hline S. epidermidis & $66.7 .0 \pm 28.9$ & $16.7 \pm 7.2$ & $16.7 \pm 7.2$ & $33.3 \pm 14.4$ & $66.7 \pm 28.9$ & $16.7 \pm 7.2$ & $16.7 \pm 7.2$ & $50.0 \pm 0.0$ \\
\hline \multicolumn{9}{|c|}{ Fungus } \\
\hline C. albicans & $>400$ & $333.3 \pm 115.5$ & $266.7 \pm 115.5$ & $>400$ & $>400$ & $333.3 \pm 115.5$ & $266.7 \pm 115.5$ & $>400$ \\
\hline
\end{tabular}

MIC: minimum inhibitory concentration, MBC: minimum bactericidal concentration, and MFC: minimum fungicidal concentration. MIC means were compared using the Friedman test $(p<0.001)$ and Wilcoxon signed-rank test with Bonferroni adjustment: $A$. dorsata and A. mellifera $(p<0.001)$, A. dorsata and A. cerana $(p<0.001)$, A. dorsata and A. florea $(p=0.013)$, A. mellifera and A. cerana $(p=0.395)$, A. mellifera and $A$. florea $(p<0.001)$, and $A$. cerana and $A$. florea $(p<0.001)$. The MBC/MFC means were compared using the Friedman test $(p<0.001)$ and Wilcoxon signed-rank test with Bonferroni adjustment: A. dorsata and A. mellifera $(p<0.001)$, A. dorsata and A. cerana ( $p<0.001)$, A. dorsata and A. florea $(p=0.028)$, A. mellifera and A. cerana $(p=0.066)$, A. mellifera and $A$. florea $(p<0.001)$, and A. cerana and A. florea $(p<0.001)$. $\mathrm{a}>\mathrm{b}>\mathrm{c}$ in potency.

\subsection{Antimicrobial Activities of Four Melittin Peptides}

In this experiment, four melittin peptides were synthesized to be tested with nine microorganisms. The MIC and MBC/MFC values of all the melittin peptides against the Gram-positive bacteria were lower in concentration compared to the values with regard to the Gram-negative bacteria and yeast, which are shown in Table 5. It was noticed that the MIC and MBC values of all the melittin peptides against $B$. subtilis showed high concentrations at $\geq 400 \mu \mathrm{g} / \mathrm{mL}$, while S. epidermis was the most susceptible to ACM, with both the MIC and MBC values at $12.5 \pm 0.0 \mu \mathrm{g} / \mathrm{mL}$. All the melittin peptides were compared with regard to their potential antimicrobial activity, which showed significant 
differences at $p<0.001$. The MIC value of ACM showed the highest activity against the tested microorganisms compared to that of AMM, AFM, and ADM at $p<0.05$; a similar trend was found regarding the MBC/MFC values. The comparison between AMM and AFC did not produce statistically significant different results in regard to the MIC and MBC/MFC values ( $p=0.154$ and 0.146 , respectively). While the MIC and MBC/MFC values of AMM showed statistically significant differences with $\operatorname{ADM}(p=0.011)$, the MIC value of AFC was not statistically significant with ADM ( $p=0.107)$.

Table 5. Minimum inhibitory concentrations (MICs) and minimum bactericidal concentrations (MBCs) of melittin from four honey bee species against pathogenic bacteria.

\begin{tabular}{|c|c|c|c|c|c|c|c|c|}
\hline \multirow{2}{*}{ Microorganism } & \multicolumn{4}{|c|}{ MIC $(\mu \mathrm{g} / \mathrm{mL})$} & \multicolumn{4}{|c|}{$\mathrm{MBC} / \mathrm{MFC}(\mu \mathrm{g} / \mathrm{mL})$} \\
\hline & $\mathrm{ADM}^{\mathrm{c}}$ & $\mathbf{A M M}^{\mathrm{b}}$ & $\mathrm{ACM}^{\mathrm{a}}$ & $\operatorname{AFM}^{b, c}$ & $\mathrm{ADM}^{\mathrm{c}}$ & $\mathrm{AMM}^{\mathrm{a}, \mathrm{b}}$ & $\mathrm{ACM}^{\mathrm{a}}$ & $\mathbf{A F M}^{\mathbf{b}}$ \\
\hline \multicolumn{9}{|c|}{ Gram-negative bacteria } \\
\hline E. coli & $>400$ & $>400$ & $400 \pm 0.0$ & $>400$ & $>400$ & $>400$ & $>400$ & $>400$ \\
\hline K. pneumonia & $>400$ & $>400$ & $>400$ & $>400$ & $>400$ & $>400$ & $>400$ & $>400$ \\
\hline S. typhimurium & $>400$ & $>400$ & $>400$ & $>400$ & $>400$ & $>400$ & $>400$ & $>400$ \\
\hline \multicolumn{9}{|c|}{ Gram-positive bacteria } \\
\hline B. subtilis & $>400$ & $>400$ & $400 \pm 0.0$ & $>400$ & $>400$ & $>400$ & $400 \pm 0.0$ & $>400$ \\
\hline M. luteus & $50 \pm 0.0$ & $25 \pm 0.0$ & $25 \pm 0.0$ & $25 \pm 0.0$ & $50 \pm 0.0$ & $25 \pm 0.0$ & $25 \pm 0.0$ & $25 \pm 0.0$ \\
\hline S. aureus & $200 \pm 0.0$ & $50 \pm 0.0$ & $50 \pm 0.0$ & $50 \pm 0.0$ & $200 \pm 0.0$ & $50 \pm 0.0$ & $50 \pm 0.0$ & $50 \pm 0.0$ \\
\hline$M R S A$ & $400 \pm 0.0$ & $100 \pm 0.0$ & $100 \pm 0.0$ & $200 \pm 0.0$ & $>400$ & $100 \pm 0.0$ & $100 \pm 0.0$ & $200 \pm 0.0$ \\
\hline S. epidermidis & $50 \pm 0.0$ & $25 \pm 0.0$ & $12.5 \pm 0.0$ & $50 \pm 0.0$ & $50 \pm 0.0$ & $25 \pm 0.0$ & $12.5 \pm 0.0$ & $50 \pm 0.0$ \\
\hline \multicolumn{9}{|c|}{ Fungus } \\
\hline C. albicans & $>400$ & $>400$ & $>400$ & $>400$ & $>400$ & $>400$ & $>400$ & $>400$ \\
\hline
\end{tabular}

MIC: minimum inhibitory concentration, MBC: minimum bactericidal concentration, and MFC: minimum fungicidal concentration. MIC means were compared using the Friedman test $(p<0.001)$ and Wilcoxon signed-rank test with Bonferroni adjustment: ADM and AMM $(p=0.011), \operatorname{ADM}$ and $\operatorname{ACM}(p=0.001), \operatorname{ADM}$ and AFM $(p=0.107), \operatorname{AMM}$ and ACM $(p=0.034), \operatorname{AMM}$ and AFM $(p=0.154)$, and ACM and $\operatorname{AFM}(p=0.011)$. The MBC/MFC means were compared using the Friedman test $(p<0.001)$ and Wilcoxon signed-rank test with Bonferroni adjustment: ADM and AMM ( $p=0.011), \operatorname{ADM}$ and ACM $(p=0.004), \operatorname{ADM}$ and AFM $(p=0.042), \operatorname{AMM}$ and ACM $(p=0.146), \operatorname{AMM}$ and $\operatorname{AFM}(p=0.146)$, and $\operatorname{ACM}$ and $\operatorname{AFM}(p=0.042) .{ }^{\mathrm{a}}>^{\mathrm{b}}>^{\mathrm{c}}$ in potency.

\subsection{Comparison of Antimicrobial Activity between Venoms and Their Melittin Peptides}

Gentamycin showed a lower concentration of MIC and MBC/MFC against almost all the bacteria than all the crude venoms or their melittin peptides. For example, M. luteus and MRSA were inhibited by all the crude venoms or their melittin peptides at lower concentrations than gentamycin. Incredibly, the crude venom of A. mellifera and A. cerana, as well as the melittin peptide of $A$. florea, showed statistically significant differences in terms of the MIC and MBC/MFC when compared with gentamycin at $p<0.05$ (Figure 4). Comparisons between the crude venoms and their melittin peptides in all honey bee species against microorganisms did not reveal any statistically significant different results, except A. dorsata against MRSA (melittin produced a lower MIC value than the crude venom, $p=0.043$ ), $A$. mellifera, and $A$. cerana against $C$. albicans (crude venom produced lower MIC and MFC values than the melittin peptide; MIC, $p=0.037$ and MFC, $p=0.048$ ) (Figure 4). While the crude venom of all honey bee species seemed to strongly inhibit $B$. subtilis rather than their melittin, this finding was not statistically significantly different. 

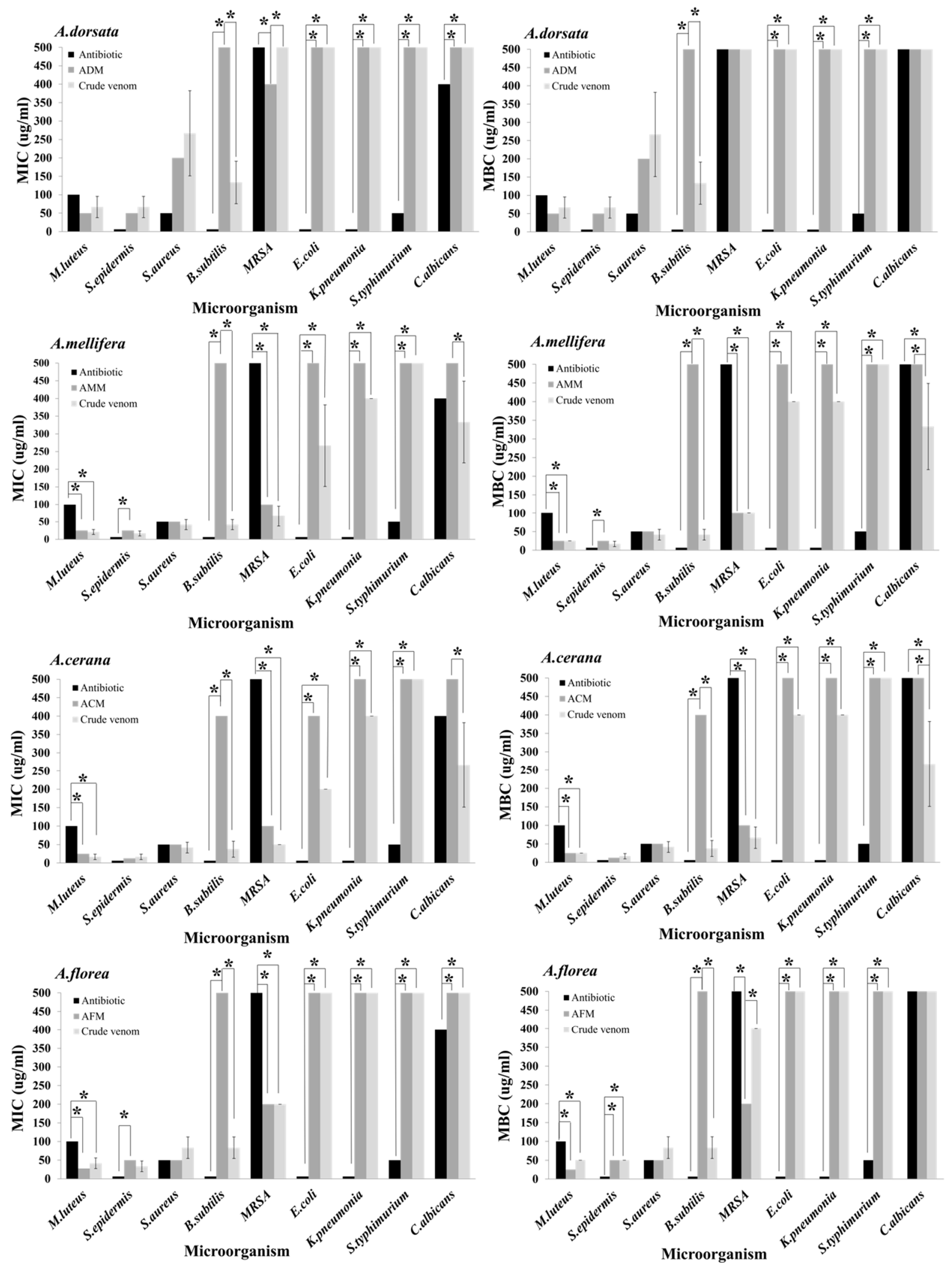

Figure 4. Comparison of the MIC and MBC/MFC (mean $\pm \mathrm{SD}$ ) among the crude venom, melittin peptide, and antibiotics (positive controls) in each honey bee species against the pathogenic bacteria. Asterisks $\left({ }^{*}\right)$ represent statistically significant differences at $p<0.05$. 


\section{Discussion}

The sequences of the melittin of four honey bee species were revealed via the PCR technique, and it was found that the melittin of $A$. mellifera and $A$. cerana shared high similarities but displayed some differences with $A$. dorsata and $A$. florea. This investigation suggests that the genetic differences in melittin are due to the evolution of honey bee species. A. mellifera and A. cerana possess a close relationship via their genetics, and they are a multiple-comb cavity nesting species, while $A$. dorsata and $A$. florea are single-comb open-air nesting species [14]. Honey bee venom has been previously reported to kill both Gram-positive and Gram-negative bacteria. El-Seedi et al. [2] suggested that Gram-positive bacteria are more sensitive to melittin than Gram-negative bacteria due to the nature of the cell membrane layer. Melittin peptides can enter Gram-positive bacteria through the peptidoglycan layer of the Gram-positive cell membrane with less effort than in Gramnegative cells, which have a layer of lipopolysaccharides over the peptidoglycan layer to protect their membrane. In addition, the proline residue in position 14 of the melittin also plays a crucial role in the antimicrobial activity of melittin. Han et al. [5] reported that Korean A. mellifera showed high antimicrobial activity against Gram-positive mastitis pathogens, especially $S$. aureus and MRSA, as it was shown to inhibit Gram-negative bacteria (E. coli). Moreover, we also found that extracted venom from $A$. cerana showed the highest antimicrobial activity, followed by $A$. mellifera, A. florea, and A. dorsata. This result was in agreement with the findings of Surendra et al. [15], who measured the antimicrobial activity of venom in Apis using a disk diffusion assay, and A. cerana venom showed a higher inhibitory zone. Honey bee venom contains several bioactive substances, and the principal component is melittin, which many studies have reported as having high antimicrobial activity [16-18]. The negative charge of the surface of the lipid membrane of microorganisms is attracted to the positive charge of melittin. It can be inserted into the lipid bilayer and can lead to pore formation in the membrane [19]. Additionally, 7-dehydrocholesterol, stigmasterol, cholesterol, and ergosterol can decrease a membrane's sensitivity to melittin [20]. Therefore, yeast is not sensitive to melittin, because the yeast plasma membrane contains large amounts of ergosterol [21]. Most Gram-positive bacteria are more sensitive to venom than Gram-negative bacteria because of the differences in their cell membrane structures. A single plasma membrane binds Gram-positive bacteria, whereas Gram-negative bacteria are bound by two membranous structures (the inner and outer membrane), showing different compositions [22,23].

In this experiment, the antimicrobial activities of crude venom and each melittin peptide (ADM, AMM, and AFM) were determined against standard human pathogenic microorganisms, including Gram-positive (Bacillus subtilis, Micrococcus luteus, Staphylococcus aureus, S. aureus MRSA, and S. epidermidis) and Gram-negative bacteria (Escherichia coli, Klebsiella pneuminiae, and Salmonella typhimurium) or a fungus (Candida albicans). Singlenucleotide polymorphisms (SNP) have been studied in the melittin gene of A. mellifera and A. cerana, and it was found that the novel SNP of the melittin gene exists in two honey bee species [12]. Hence, a novel melittin peptide (ACM) was tested for antimicrobial activity in our experiment. The results showed that microorganisms were the most susceptible to ACM, followed by AMM, AFC, and ADM. The critical factors for antimicrobial peptide efficiency were revealed, including sequence, size, structuring, charge, amphipathicity, and hydrophobicity [24]. The four positive net charges of ADM had lower antimicrobial activity than the remaining three peptides with five positive net charges. Previous research found that decreasing the protein net charge to +4 significantly reduced the antimicrobial activity of V13K for both Gram-positive and Gram-negative bacteria [25].

Furthermore, increasing the charge resulted in stronger peptide binding to the negatively charged membranes [26], implying that a higher net charge leads to an increase in antimicrobial activity. The hydrophobicity of AFM was similar to AMM, but the secondary structure of AMM had a higher $\alpha$-helical potency and lower $\beta$-sheet in the partial structure than AFM. The effect of the peptide secondary structure on the antimicrobial activity has been previously studied by designing an $\alpha$-helical peptide with a higher helical propensity 
than the original peptide, a $\beta$-sheet peptide, and a random coiled peptide. The $\alpha$-helical conformation peptide showed higher antimicrobial activity, but the $\beta$-sheet and random coiled peptide lost their efficiency [27]. AMM and ACM displayed a difference in one amino acid residue at the 18th position in the melittin peptide; in AMM, this was serine (S), and in $\mathrm{ACM}$, this was asparagine $(\mathrm{N})$. AMM exhibited higher hydrophobicity than ACM. In 2014, Park et al. [12] found that Mel-(S) showed more antimicrobial activity than Mel-(N) at $0.25 \mu \mathrm{M}$, but some E. coli was still alive in this concentration.

In contrast, we found that ACM showed higher antimicrobial activity than AMM and ultimately killed the bacteria in some bacteria species. This result may be explained by the fact that an increase in the hydrophobicity increased the membrane disruption [28-30] but only if a high concentration of peptide was the cause of self-aggregation [10]. The self-aggregation in the peptide decreased the antimicrobial activity [31].

By comparing types of venom and their melittin peptides, we found that the melittin of both A. florea and A. dorsata showed stronger activity than their extracted venoms. The significant potency may be derived from melittin in their extracted venom. On the other hand, the antimicrobial effects of the A. mellifera and A. cerana venoms were similar to their melittins. Interestingly, an equal concentration of honey bee venoms and their melittins showed similarities in antimicrobial efficiency. Their pure melittins should have higher activity than the crude honey bee venoms.

Moreover, honey bee venoms extracted from A. cerana and A. mellifera were used at lower concentrations than their melittins against some Gram-negative bacteria and yeast. All the extracted venoms from four honey species presented higher antimicrobial activities than their melittins against $B$. subtilis. These results indicated that bee venoms extracted from different honey bee species vary in their compositions. The amount and composition of the lipid, protein, carbohydrate, and alkaline phosphatase were usually highest in A. cerana, followed by A. mellifera and A. florea. However, the amount of melittin in the venoms did not reflect the antimicrobial activity, as the melittin contained in $A$. dorsata, A. mellifera, A. florea, and A. cerana were $95.8 \pm 3.2 \%, 76.5 \pm 1.9 \%, 66.3 \pm 8.6 \%$, and $56.8 \pm 1.8 \%$, respectively [8], and these values were not related to the antimicrobial properties. Another reason is that crude venom contains other antimicrobial substances, mainly minor components that could synergize with melittin and increase the antimicrobial activity. Phospholipase A2 (PLA2) is one such antimicrobial substance in the venom. sPLA2-IIA has been reported to display activity against Gram-positive and Gram-negative bacteria [32] and B. antiracist, which produced a capsule [33].

Furthermore, it killed both methicillin-resistant staphylococci and vancomycin-resistant enterococci [34]. Additionally, the variability in bee venom composition is related to the honey bee species, stage, geographical origin, and condition, which also affect the antimicrobial activity. The bee venoms and melittin peptides may be potential sources of antimicrobial agents against Gram-positive and antibiotic-resistant bacteria. However, the antimicrobial activity derived from in vitro systems cannot cover all the biological variables found within the human body. The factors affecting the reliability of in vitro testing systems include the limitations in interpreting MIC, MBC, or MFC data due to the in vitro test conditions that cannot counterfeit the host environment and the variability of the testing media. Hence, in vivo studies of the kinetic, toxicity, and molecular mechanisms are still needed before further applications can be developed.

\section{Materials and Methods}

\subsection{Collection and Preparation of the Bee Venom Extracts}

Honey bee colonies were collected from 2016 to 2017, which included four honey bee species and three colonies of each species. Venom reservoirs were extracted by dissecting the stinging apparatus, and they were disrupted under light pressure on a glass slide using a sterile glass rod. The honey bee venom was washed in sterile deionized water, centrifuged at $10,000 \times \mathrm{g}$ at $4{ }^{\circ} \mathrm{C}$ for $5 \mathrm{~min}$ to remove insoluble materials, and the supernatant was collected [15]. All samples were lyophilized and dissolved by phosphate-buffered saline 
(PBS), pH 7.4. The crude venom solution $(1 \mathrm{mg} / \mathrm{mL})$ of each honey bee species was filtered using a $0.22-\mu \mathrm{m}$ syringe filter and kept at $-20^{\circ} \mathrm{C}$ before further experiments.

\subsection{Genomic DNA Isolation}

Total genomic DNA was isolated from four honey bee species using the ISOLATE II Genomic DNA Kit (Bioline, London, UK) in accordance with the manufacturer's protocols. The DNA was stored at $-80^{\circ} \mathrm{C}$ until required.

\subsection{Melittin Sequences}

The extracted genomic DNA was used as a template for amplified melittin sequencing. This study designed the primers using Geneious version 8.1.8 (forward primer: 5' GGA ATT CCA TAT GGG AAT TGG AGC AGT TC $3^{\prime}$ and reverse primer: $5^{\prime}$ GGC GCG GAT CCT TAT TAC TGT TGC CT3'). The melittin gene was synthesized using the KOD Hot Start Master Mix (Merck Millipore, Darmstadt, Germany). The thermal cycling conditions were as follows: one cycle of initial denaturation at $95^{\circ} \mathrm{C}$ for $2 \mathrm{~min}, 35$ cycles of denaturation at $95^{\circ} \mathrm{C}$ for $20 \mathrm{~s}$, annealing at $55^{\circ} \mathrm{C}$ for $10 \mathrm{~s}$, and extension at $70^{\circ} \mathrm{C}$ for $10 \mathrm{~s}$. The PCR products were purified using the PureLink ${ }^{\circledR}$ Gel Extraction Kit (Life Technologies, Carlsbad, CA, USA) and sequencing (Macrogen Inc., Seoul, Korea).

\subsection{Peptide Synthesis}

Four sequences of the melittin peptide were chemically synthesized by SynPeptide Co., Ltd. (Shanghai, China) based on the deduced amino acid sequences, as shown in Table 1. A melittin working stock solution was prepared by dissolution in phosphate-buffered saline $(\mathrm{pH} 7.7)$ at a concentration of $1 \mathrm{mg} / \mathrm{mL}$ for the antimicrobial and antioxidant assays.

\subsection{Tested Microorganisms}

The antimicrobial properties of the crude venom from four honey bee species and melittin peptides were tested against five Gram-positive bacteria, including Staphylococcus aureus TISTR 517, Staphylococcus epidermidis DMST 15505, methicillin-resistant Staphylococcus aureus (MRSA) DMST 20625, Bacillus subtilis DMST 15896, and Micrococcus luteus DMST 15503, as well as three Gram-negative bacteria, including Klebsiella pneumoniae DMST 8216, Salmonella typhimurium DMST 562, and Escherichia coli ATCC 25922, and Candida albicans TISTR 5554 (yeast). All microorganisms were purchased from the American Type Culture Collection (ATCC), the Department of Medical Sciences Thailand (DMST), and the Thailand Institute of Scientific and Technological Research (TISTR).

\subsection{Detection of Minimum Inhibitory and Minimum Bactericidal Concentrations (MIC and MBC)}

All microorganisms that were used for the determination of the minimum inhibitory concentrations (MICs) were freshly prepared before testing. Each culture was transferred to a sterile PBS, and the turbidity was adjusted by the 0.5 McFarland Standard (Himedia, Mumbai, India). Each microorganism was added to the crude venom and melittin peptides at different concentrations (3.12-400 $\mu \mathrm{g} / \mathrm{mL}$ ) in 96-well plates following the Clinical and Laboratory Standards Institute (CLSI) guidelines [35,36]. Sterile PBS saline was used as a negative control, while $1 \mathrm{mg} / \mathrm{mL}$ of gentamicin (Merck KGaA, Darmstadt, Germany) and nystatin (Bio Basic Canada Inc., Markham, ON, Canada) was used as a positive control for the bacteria and yeast, respectively. All bacteria were incubated at $37^{\circ} \mathrm{C}$ for $24 \mathrm{~h}$, and the yeast was cultured at $30^{\circ} \mathrm{C}$ for $48 \mathrm{~h}$. The inhibition of microbial growth was determined by measuring the absorbance at $600 \mathrm{~nm}$. The lowest concentration of venom or melittin peptide that inhibited microbial growth was the MIC. To determine the MBC/MFC, $0.1 \mathrm{~mL}$ of MIC with no microbial growth was spread onto Mueller-Hinton agar (HiMedia, Mumbai, India) at $37^{\circ} \mathrm{C}$ for $24 \mathrm{~h}$ (for bacteria) or Sabouraud's dextrose agar (HiMedia, Mumbai, India) at $30^{\circ} \mathrm{C}$ for $48 \mathrm{~h}$ (for yeast). The final concentration of venom or melittin peptide that did not appear to contain microbial growth was the MBC/MFC. 


\subsection{Bioinformatics Analysis for Melittin Structures}

The melittin gene sequences from $A$. dorsata and A. florea were obtained through this study, while the A. mellifera and A. cerana melittin sequences were retrieved from the National Center for Biotechnology Information (NCBI: https:/ / www.ncbi.nlm.nih.gov/) (accessed on 10 March 2016) (Table 1). The deduction of the amino acid sequences of melittin and protein alignment were performed by using Geneious version 10.2.3. The secondary structures of all the melittins were predicted using SOPMA [37]. The amino acid compositions and physicochemical parameters, such as the molecular weights, predicted pI, GRAVY, instability index, and hydropathicity, were estimated using ProtParam [38] (http:/ / web.expasy.org/protparam/) (accessed on 26 April 2021). For the analysis of the net charge, hydrophobic moment $(\mathrm{mH})$, hydrophobicity $(\mathrm{H})$, and melittin helical wheel plot, we used the online program HeliQuest [13] (http:/ / heliquest.ipmc.cnrs.fr/cgi-bin/ ComputParamsV2.py) (accessed on 26 April 2021).

\subsection{Statistical Analysis}

All the data analyses were performed using IBM SPSS Statistics Version 25.0 (IBM Corp., Armonk, NY, USA) and checked for normality of distribution. The Freidman and Wilcoxon signed-rank tests with Bonferroni adjustment for multiple comparisons were used to test the MIC and MBC/MFC data of the crude venoms against pathogenic microbes and test the MIC and MBC/MFC data of melittin peptides against pathogenic microbes as well. Comparisons of the MIC and MBC data among the three treatments in each honey bee species (crude venom, melittin peptide, and antibiotic) were made using the Kruskal-Wallis test followed by the Dunn-Bonferroni multiple comparison test. The level of significance was concluded to be $p<0.05$.

\section{Conclusions}

To summarize, we successfully investigated melittin genes from four species of honey bees. Most of the melittins were similar in terms of size and the number of amino acids. Melittin and crude venom from A. cerana displayed the most antimicrobial activity against Gram-positive bacteria and MRSA compared to the other honey bees. Nevertheless, the antimicrobial activity of honey bee venoms and melittins against Gram-negative bacteria and fungi is limited. Slight differences in the amino acid sequence, size, structuring, charge, amphipathicity, and hydrophobicity may play an essential role in the melittin properties. The present investigation revealed that bee venoms and melittin peptides, the primary component of bee venom, also act as an antimicrobial peptide in bee venom that could be a promising candidate for use as an antimicrobial agent.

Author Contributions: Conceptualization, J.M. and P.C.; methodology, J.M. and P.C.; software, J.M.; validation, J.M., S.K., and W.M.; formal analysis, J.M.; investigation, P.C.; resources, P.C.; data curation, J.M., S.K., and W.M.; writing—original draft preparation, J.M., P.C., S.K., and W.M.; writingreview and editing, J.M., P.C., and W.M.; visualization, P.C.; supervision, P.C.; project administration, P.C.; and funding acquisition, P.C. All authors have read and agreed to the published version of the manuscript.

Funding: This research was funded by the Chiang Mai University fund, the National Research Council of Thailand, and King Mongkut's University of Technology North Bangkok, contract No. KMUTNB-63- KNOW-013.

Institutional Review Board Statement: Not applicable.

Data Availability Statement: The data presented in this study are available upon request from the corresponding author.

Acknowledgments: The authors would like to thank the bee protection laboratory members who kindly assisted us through their contributions of honey bee samples.

Conflicts of Interest: The authors declare no conflict of interest. 


\section{References}

1. Surendra, N.S.; Jayaram, G.N.; Reddy, M.R.S.; Ravikumar, H. Comparative morphometric studies of the sting apparatus of the worker bees of four different Apis species (Apis dorsata, Apis mellifera, Apis cerana and Apis florea). J. Apic. Res. 2013, 52, 74-80. [CrossRef]

2. $\quad$ El-Seedi, H.; El-Wahed, A.; Yosri, N.; Musharraf, S.G.; Chen, L.; Moustafa, M.; Zou, X.; Al-Mousawi, S.; Guo, Z.; Khatib, A. Antimicrobial properties of Apis mellifera's bee venom. Toxins 2020, 12, 451. [CrossRef] [PubMed]

3. Son, D.J.; Lee, J.W.; Lee, Y.H.; Song, H.S.; Lee, C.K.; Hong, J.T. Therapeutics. Therapeutic application of anti-arthritis, painreleasing, and anti-cancer effects of bee venom and its constituent compounds. Pharmacol. Ther. 2007, 115, 246-270. [CrossRef]

4. Sobral, F.; Sampaio, A.; Falcão, S.; Queiroz, M.J.R.; Calhelha, R.C.; Vilas-Boas, M.; Ferreira, I.C.F.R. Chemical characterization, antioxidant, anti-inflammatory and cytotoxic properties of bee venom collected in Northeast Portugal. Food Chem. Toxicol. 2016, 94, 172-177. [CrossRef] [PubMed]

5. Han, S.-M.; Lee, K.-G.; Yeo, J.-H.; Kweon, H.-Y.; Kim, B.-S.; Kim, J.-M.; Baek, H.-J.; Kim, S.-T. Antibacterial activity of the honey bee venom against bacterial mastitis pathogens infecting dairy cows. Int. J. Ind. Entomol. 2007, 14, 137-142.

6. Lee, S.-B. Antifungal activity of bee venom and sweet bee venom against clinically isolated Candida albicans. J. Pharmacopunct. 2016, 19, 45. [CrossRef] [PubMed]

7. Mata, É.C.G.d.; Mourão, C.B.F.; Rangel, M.; Schwartz, E.F.J.J.o.V.A.; Diseases, T.i.T. Antiviral activity of animal venom peptides and related compounds. J. Venom. Anim. Toxins Incl. Trop. Dis. 2017, 23, 3. [CrossRef] [PubMed]

8. Somwongin, S.; Chantawannakul, P.; Chaiyana, W. Antioxidant activity and irritation property of venoms from Apis species. Toxicon 2018, 145, 32-39. [CrossRef]

9. Popplewell, J.; Swann, M.; Freeman, N.; McDonnell, C.; Ford, R.C. Quantifying the effects of melittin on liposomes. Biochim. Biophys. Acta BBA-Biomembr. 2007, 1768, 13-20. [CrossRef]

10. Brown, L.R.; Lauterwein, J.; Wüthrich, K. High-resolution 1H-NMR studies of self-aggregation of melittin in aqueous solution. Biochim. Biophys. Acta BBA-Protein Struct. 1980, 622, 231-244. [CrossRef]

11. Jamasbi, E.; Batinovic, S.; Sharples, R.A.; Sani, M.-A.; Robins-Browne, R.M.; Wade, J.D.; Separovic, F.; Hossain, M.A. Melittin peptides exhibit different activity on different cells and model membranes. Amino Acids 2014, 46, 2759-2766. [CrossRef] [PubMed]

12. Park, D.; Jung, J.W.; Lee, M.O.; Lee, S.Y.; Kim, B.; Jin, H.J.; Kim, J.; Ahn, Y.-J.; Lee, K.W.; Song, Y.S.; et al. Functional characterization of naturally occurring melittin peptide isoforms in two honey bee species, Apis mellifera and Apis cerana. Peptides 2014, 53, 185-193. [CrossRef] [PubMed]

13. Gautier, R.; Douguet, D.; Antonny, B.; Drin, G. HELIQUEST: A web server to screen sequences with specific $\alpha$-helical properties. Bioinformatics 2008, 24, 2101-2102. [CrossRef]

14. Garnery, L.; Vautrin, D.; Cornuet, J.M.; Solignac, M. Phylogenetic relationships in the genus Apis inferred from mitochondrial DNA sequence data. Apidologie 1991, 22, 87-92. [CrossRef]

15. Surendra, N.S.; Jayaram, G.N.; Reddy, M.S. Antimicrobial activity of crude venom extracts in honeybees (Apis cerana, Apis dorsata, Apis florea) tested against selected pathogens. Afr. J. Microbiol. Res. 2011, 5, 2765-2772. [CrossRef]

16. Owen, M.D.; Pfaff, L.A. Melittin synthesis in the venom system of the honey bee (Apis mellifera L.). Toxicon 1995, 33, 1181-1188. [CrossRef]

17. Banks, B.E.C.; Shipolini, R.A. 7-Chemistry and Pharmacology of Honey-bee Venom A2-Piek, Tom. In Venoms of the Hymenoptera; Academic Press: Cambridge, MA, USA, 1986; pp. 329-416.

18. Dotimas, E.M.; Hider, R.C. Honeybee Venom. Bee World 1987, 68, 51-70. [CrossRef]

19. Raghuraman, H.; Chattopadhyay, A. Melittin: A Membrane-active Peptide with Diverse Functions. Biosci. Rep. 2007, 27, 189. [CrossRef]

20. Feigin, A.M.; Teeter, J.H.; Brand, J.G. The Influence of Sterols on the Sensitivity of Lipid Bilayers to Melittin. Biochem. Biophys. Res. Commun. 1995, 211, 312-317. [CrossRef] [PubMed]

21. Zinser, E.; Sperka-Gottlieb, C.D.; Fasch, E.V.; Kohlwein, S.D.; Paltauf, F.; Daum, G. Phospholipid synthesis and lipid composition of subcellular membranes in the unicellular eukaryote Saccharomyces cerevisiae. J. Bacteriol. 1991, 173, 2026-2034. [CrossRef] [PubMed]

22. Chatterjee, S.N.; Chaudhuri, K. (Eds.) Gram-Negative Bacteria: The cell Membranes. In Outer Membrane Vesicles of Bacteria; Springer: Berlin/Heidelberg, Germany, 2012; pp. 15-34.

23. Navarre, W.W.; Schneewind, O. Surface Proteins of Gram-Positive Bacteria and Mechanisms of Their Targeting to the Cell Wall Envelope. Microbiol. Mol. Biol. Rev. 1999, 63, 174-229. [CrossRef]

24. Tossi, A.; Sandri, L.; Giangaspero, A. Amphipathic, $\alpha$-helical antimicrobial peptides. Pept. Sci. 2000, 55, 4-30. [CrossRef]

25. Jiang, Z.; Vasil, A.I.; Hale, J.D.; Hancock, R.E.W.; Vasil, M.L.; Hodges, R.S. Effects of net charge and the number of positively charged residues on the biological activity of amphipathic $\alpha$-helical cationic antimicrobial peptides. Pept. Sci. 2008, 90, 369-383. [CrossRef]

26. Matsuzaki, K.; Nakamura, A.; Murase, O.; Sugishita, K.-i.; Fujii, N.; Miyajima, K. Modulation of Magainin 2-Lipid Bilayer Interactions by Peptide Charge. Biochemistry 1997, 36, 2104-2111. [CrossRef]

27. Thành, M.X. Effect of Secondary Structure on Biological Activities of Antimicrobial Peptides. VNU J. Sci. Nat. Sci. Technol. 2015, $31,44-53$. 
28. Ringstad, L.; Andersson Nordahl, E.; Schmidtchen, A.; Malmsten, M. Composition Effect on Peptide Interaction with Lipids and Bacteria: Variants of C3a Peptide CNY21. Biophys. J. 2007, 92, 87-98. [CrossRef] [PubMed]

29. Wieprecht, T.; Dathe, M.; Beyermann, M.; Krause, E.; Maloy, W.L.; MacDonald, D.L.; Bienert, M. Peptide Hydrophobicity Controls the Activity and Selectivity of Magainin 2 Amide in Interaction with Membranes. Biochemistry 1997, 36, 6124-6132. [CrossRef]

30. Rosenfeld, Y.; Lev, N.; Shai, Y. Effect of the Hydrophobicity to Net Positive Charge Ratio on Antibacterial and Anti-Endotoxin Activities of Structurally Similar Antimicrobial Peptides. Biochemistry 2010, 49, 853-861. [CrossRef] [PubMed]

31. Chen, Y.; Guarnieri, M.T.; Vasil, A.I.; Vasil, M.L.; Mant, C.T.; Hodges, R.S. Role of Peptide Hydrophobicity in the Mechanism of Action of $\alpha$-Helical Antimicrobial Peptides. Antimicrob. Agents Chemother. 2007, 51, 1398-1406. [CrossRef] [PubMed]

32. Nevalainen, T.J.; Graham, G.G.; Scott, K.F. Antibacterial actions of secreted phospholipases A2. Review. Biochim. Et Biophys. Acta BBA-Mol. Cell Biol. Lipids 2008, 1781, 1-9. [CrossRef] [PubMed]

33. Gimenez, A.P.; Wu, Y.-Z.; Paya, M.; Delclaux, C.; Touqui, L.; Goossens, P.L. High bactericidal efficiency of type IIA phospholipase A2 against Bacillus anthracis and inhibition of its secretion by the lethal toxin. J. Immunol. 2004, 173, 521. [CrossRef] [PubMed]

34. Grönroos, J.O.; Laine, V.J.O.; Janssen, M.J.W.; Egmond, M.R.; Nevalainen, T.J. Bactericidal Properties of Group IIA and Group V Phospholipases A2. J. Immunol. 2001, 166, 4029. [CrossRef] [PubMed]

35. Clinical and Laboratory Standards Institute. Reference Method for Broth Dilution Antifungal Susceptibility Testing of Yeasts: Third Informational Supplement M27-S3; CLSI: Wayne, PA, USA, 2008.

36. Wikler, M.A. Methods for Dilution Antimicrobial Susceptibility Tests for Bacteria That Grow Aerobically: Approved Standard; CLSI: Wayne, PA, USA, 2006; Volume 26, p. M7-A7.

37. Geourjon, C.; Deléage, G. SOPMA: Significant improvements in protein secondary structure prediction by consensus prediction from multiple alignments. Bioinformatics 1995, 11, 681-684. [CrossRef] [PubMed]

38. Gasteiger, E.; Hoogland, C.; Gattiker, A.; Duvaud, S.E.; Wilkins, M.R.; Appel, R.D.; Bairoch, A. Protein Identification and Analysis Tools on the ExPASy Server. In The Proteomics Protocols Handbook; Walker, J.M., Ed.; Humana Press: Totowa, NJ, USA, 2005; pp. 571-607. 